\title{
miR-125b-2 is a potential oncomiR on human chromosome 21 in megakaryoblastic leukemia
}

\author{
Jan-Henning Klusmann, ${ }^{1,2,7}$ Zhe Li, ${ }^{1,3,4,7}$ Katarina Böhmer, ${ }^{2}$ Aliaksandra Maroz, ${ }^{2}$ Mia Lee Koch, ${ }^{2}$ \\ Stephan Emmrich, ${ }^{2}$ Frank J. Godinho, ${ }^{1,5}$ Stuart H. Orkin, $, 3,5,6,8$ and Dirk Reinhardt ${ }^{2}$ \\ ${ }^{1}$ Division of Hematology/Oncology, Children's Hospital Boston, Boston, Massachusetts 02115, USA; ${ }^{2}$ Department of Pediatric \\ Hematology/Oncology, Medical School Hannover, Hannover 30625, Germany; ${ }^{3}$ Harvard Medical School and Harvard Stem Cell \\ Institute, Boston, Massachusetts 02115, USA; ${ }^{4}$ Division of Genetics, Brigham and Women's Hospital, Boston, Massachusetts \\ 02115, USA; ${ }^{5}$ Department of Pediatric Oncology, Dana Farber Cancer Institute, Boston, Massachusetts 02115, USA; ${ }^{6}$ Howard \\ Hughes Medical Institute, Boston, Massachusetts 02115, USA
}

Children with trisomy 21/Down syndrome (DS) are at high risk to develop acute megakaryoblastic leukemia (DS$A M K L)$ and the related transient leukemia (DS-TL). The factors on human chromosome 21 (Hsa21) that confer this predisposing effect, especially in synergy with consistently mutated transcription factor GATA1 (GATA1s), remain poorly understood. Here, we investigated the role of Hsa21-encoded miR-125b-2, a microRNA (miRNA) overexpressed in DS-AMKL/TL, in hematopoiesis and leukemogenesis. We identified a function of $m i R-125 b-2$ in increasing proliferation and self-renewal of human and mouse megakaryocytic progenitors (MPs) and megakaryocytic/erythroid progenitors (MEPs). miR-125b-2 overexpression did not affect megakaryocytic and erythroid differentiation, but severely perturbed myeloid differentiation. The proproliferative effect of miR-125b-2 on MEPs accentuated the Gata1s mutation, whereas growth of DS-AMKL/TL cells was impaired upon miR-125b repression, suggesting synergism during leukemic transformation in GATA1s-mutated DS-AMKL/TL. Integrative transcriptome analysis of hematopoietic cells upon modulation of $\mathrm{miR}-125 \mathrm{~b}$ expression levels uncovered a set of $\mathrm{miR}$ $125 b$ target genes, including DICER1 and ST18 as direct targets. Gene Set Enrichment Analysis revealed that this target gene set is down-regulated in DS-AMKL patients highly expressing miR-125b. Thus, we propose miR-125b-2 as a positive regulator of megakaryopoiesis and an oncomiR involved in the pathogenesis of trisomy 21-associated megakaryoblastic leukemia.

[Keywords: Down syndrome; chromosome 21; leukemia; miRNA]

Supplemental material is available at http://www.genesdev.org.

Received August 21, 2009; revised version accepted December 23, 2009.

Numerical and structural aberrations involving human chromosome 21 (Hsa21) are the most common cytogenetic abnormalities found in childhood acute myeloid leukemia (AML). However, genes that confer oncogenic properties of Hsa21 remain incompletely understood (for review, see Malinge et al. 2009). Acute megakaryoblastic leukemia (AMKL) in children with trisomy 21 (Down syndrome [DS]; i.e., DS-AMKL) and the related antecedent, transient leukemia (DS-TL, also known as transient myeloproliferative disorder [TMD]) provide a unique context in which to address this issue (Hasle 2001; Klusmann et al. 2008). Five percent to $10 \%$ of all DS infants exhibit

\footnotetext{
${ }^{7}$ These authors contributed equally to this work.

${ }^{8}$ Corresponding author.

E-MAIL Stuart_Orkin@dfci.harvard.edu; FAX (617) 632-4367.

Article is online at http://www.genesdev.org/cgi/doi/10.1101/gad.1856210. Freely available online through the Genes \& Development Open Access option.
}

DS-TL, which resolves spontaneously in the majority of cases, but shows progression to DS-AMKL in $20 \%-30 \%$ of DS-TL patients (Klusmann et al. 2008). Acquired mutations in the hematopoietic transcription factor GATA1-encoded on chromosome X-are consistently present in the affected cells of children with DS-AMKL and DS-TL, leading to expression of a shorter GATA1 variant (GATA1s) truncated at its $\mathrm{N}$ terminus (Wechsler et al. 2002; Mundschau et al. 2003). However, neither mice nor humans with germline mutations leading to expression of GATA1s develop leukemia or myeloproliferative disease in the absence of an extra copy of Hsa21 (Li et al. 2005; Hollanda et al. 2006). The requirement for trisomy 21 in cellular transformation in DS-AMKL, therefore, appears stringent.

MicroRNAs (miRNAs) are 21- to 23-nucleotide (nt) noncoding RNAs that play crucial roles in fundamental biologic processes, including proliferation, differentiation, 
and apoptosis, by negatively regulating gene expression (for review, see Carthew and Sontheimer 2009). miRNAs are transcribed as primary miRNAs (pri-miRNAs) and processed in the nucleus by the RNase III endonuclease DROSHA to liberate $\sim 70$-nt stem loops, the precursor miRNA (pre-miRNA). The pre-miRNAs are then exported from nucleus to cytoplasm by Exportin 5/RanGTP, where further cleavage by the second RNase III enzyme DICER releases the mature miRNAs. miRNAs bind to their target mRNAs by direct base-pairing, and either repress gene translation or induce mRNA cleavage or degradation (Carthew and Sontheimer 2009). In the hematopoietic system, several miRNAs, including $m i R-150$, miR-223, and $m i R-181$, regulate lineage decisions and cellular maturation (Chen et al. 2004; Xiao et al. 2007; Johnnidis et al. 2008).

Deregulation of miRNA expression has been linked to the initiation, progression, and metastasis of human malignancies (He et al. 2005; Lu et al. 2005). Human and mouse cancers are characterized by a global reduction of mature miRNA levels compared with normal tissues (Lu et al. 2005; Kumar et al. 2007). miR-125b-2 resides along with four other known miRNAs $(m i R-99 a$, let-7c, miR155, miR-802) on Hsa21 (Fig. 1A; Landgraf et al. 2007). Recent reports suggested that $m i R-125 b$ might act as an oncogene as well as a tumor suppressor, depending on the cellular context. In prostate cancer cells, high expression levels of $m i R-125 b$ stimulate androgen-independent growth that is mediated partially by down-regulation of Bak1 (Shi et al. 2007), whereas in breast cancer, high expression levels of $m i R-125 b$ mediate down-regulation of $E R B B 2$ (HER2) and $E R B B 3$ (HER3), thereby suppressing tumor growth (Scott et al. 2007). The homolog miR-125b-1 is involved in translocations found in precursor B-cell acute lymphoblastic leukemia (pre-B ALL) and myelodysplastic syndrome (MDS) (Sonoki et al. 2005; Bousquet et al. 2008). However, the role of Hsa21-encoded miR-125b-2 in leukemogenesis has not been defined.

In this study, we investigated the role of Hsa21-encoded miR-125b-2 in hematopoiesis and leukemogenesis. Using a genetic approach, we demonstrated that, in both murine and human contexts, overexpression of $m i R-125 b-2$ led to specific hyperproliferation and enhanced self-renewal capacity of megakaryocytic progenitors (MPs) and megakaryocytic/erythroid progenitors (MEPs), without affecting their normal differentiation. This effect was aggravated further in cooperation with the oncogenic Gata1s mutation. Integrative transcriptome analysis, together with experimental validation, revealed target genes of $m i R-125 b$ in the hematopoietic system, including DICER1 and ST18 as direct targets. We showed that miR-125b was highly expressed in DS-AMKL blasts, whereas the identified target genes of $m i R-125 b$ were down-regulated. Thus, our study supports a role of $m i R$ $125 b-2$ in the regulation of megakaryopoiesis and in the pathogenesis of trisomy 21-associated megakaryoblastic leukemia, in cooperation with GATA1s. We provide evidence that $m i R-125 b-2$ exerts its oncogenic potential by blocking post-transcriptional miRNA processing through repression of DICER 1 expression and by inhibiting tumor suppressors, such as ST18.
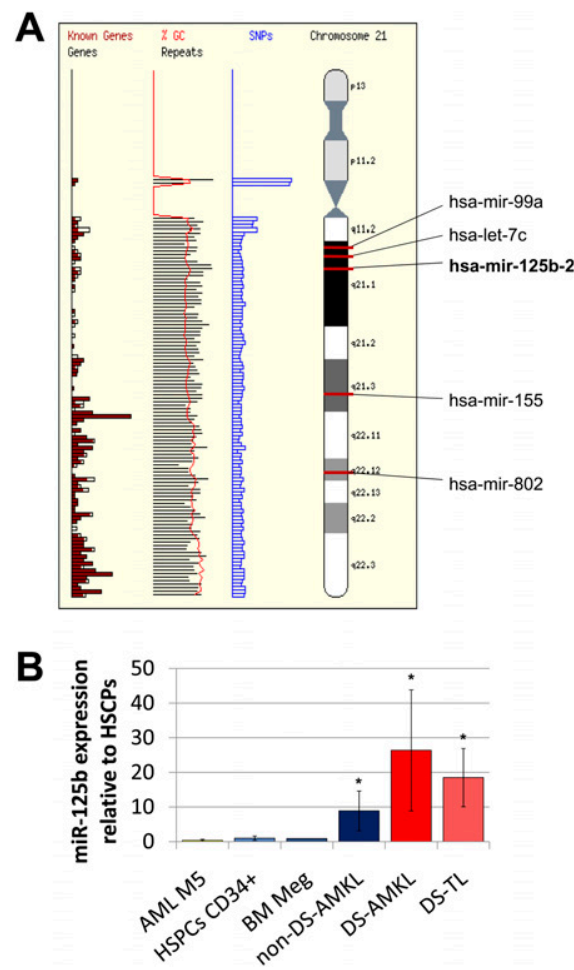

Figure 1. Hsa21-encoded miR-125b is up-regulated in AMKL patient samples. $(A)$ Schematic diagram showing the location of miR-125b-2 and four other miRNAs (miR-99a, let-7c, miR-155, and $m i R-802$ ) on human Hsa21 (http://www.ensembl.org). (B) The expression level of $m i R-125 b$ was analyzed by qRT-PCR in sorted leukemic blasts from patients with DS-AMKL $(n=5)$, DSTL $(n=4)$, non-DS-AMKL $(n=3)$, and AML FAB M5 (AML M5; $n=2)$, and in CD34 ${ }^{+}$-HSPCs $(n=2)$ and megakaryocytes (BM-Meg; $n=1$ ) from healthy donors. Data are presented as means \pm standard error of the mean (SEM) normalized to CD34 ${ }^{+}$-HSPCs. ( $\left.^{\star}\right) P_{\mathrm{U}-\mathrm{Test}}<0.05$.

\section{Results}

miR-125b is up-regulated in DS-AMKL and DS-TL

To interrogate a potential role for Hsa21-encoded miR125b-2 in trisomy 21 -associated megakaryoblastic leukemia (Fig. 1A), we first measured expression levels of $m i R$ $125 b$ in sorted leukemic blasts from patients with DSAMKL $(n=5)$, DS-TL $(n=4)$, non-DS-AMKL $(n=3)$, and AML FAB M5 $(n=2)$, and in CD34 ${ }^{+}$-HSPCs (hematopoietic stem and progenitor cells) $(n=2)$ and megakaryocytes $(n=1)$ from healthy donors. All DS-AMKL and DS-TL patients harbored a GATA1s mutation, whereas none of the non-DS-AMKL patients did (data not shown). Cytogenetic data were available for DS-AMKL $(n=3)$ and nonDS-AMKL $(n=2)$ patients (Supplemental Table S1). The expression of $m i R-125 b$ was markedly elevated in DSAMKL (26.4-fold), DS-TL (18.5-fold), and non-DS-AMKL (8.9-fold) compared with normal CD34+-HSPCs (Fig. 1B). The up-regulation of $m i R-125 b$ is not a general feature of AML, as expression was reduced (threefold) in AML FAB M5 in comparison with CD34 ${ }^{+}$-HSPCs. High levels of $m i R-125 b$ are not associated with megakaryocytic 
differentiation, as the expression level of $m i R-125 b$ in megakaryocytic cells was similar to that in $\mathrm{CD} 34^{+}$HSPCs. Expression of $m i R-125 b$ was threefold higher in DS-AMKL than non-DS-AMKL.

\section{Overexpression of miR-125b-2 increases proliferation and self-renewal of MPS}

Overexpression of $m i R-125 b$ in AMKL, and specifically in DS-AMKL and DS-TL, suggests a potential role of Hsa21encoded miR-125b-2 in AMKL pathogenesis. To test the consequences of $\mathrm{miR}-125 \mathrm{~b}-2$ overexpression on megakaryocyte development, we transduced mouse MPs from fetal livers (FLs) of embryonic day 12.5 (E12.5) embryos with retroviruses ( $M S C V$-based) containing the genomic region of $m i R-125 b-2$ or control empty vectors (LPIG containing only the miR-30 backbone [LMPIG] [Dickins et al. 2005], or MSCV-Puro). We chose to transduce fetal progenitors because we showed previously that progenitor cells at this stage of development are the likely cells of origin for transformation in DS-AMKL (Li et al. 2005). The level of mature $m i R-125 b$ attained in transduced cells was comparable with that seen in the DS-AMKL cell line (CMK), as confirmed by Northern blot (Supplemental Fig. S1A). Following transduction, we performed megakaryocytic colony-forming assays. Retroviral overexpression of $m i R-125 b-2$ markedly accelerated the proliferation of MPs, as demonstrated by increased sizes and numbers of the megakaryocyte colonyforming units (CFU-MKs) (Fig. 2A-C; Supplemental Fig. $\mathrm{S} 1 \mathrm{~B})$. Megakaryocytic differentiation proceeded normally in the presence of $m i R-125 b-2$ overexpression, as indicated by numerous acetylcholine esterase (AChE)-positive cells and large megakaryocytes with proplatelet formation within CFU-MK colonies (Fig. 2A; Supplemental Fig. S1B). To confirm that the observed effect is specific for $m i R-125 b-2$ and does not reflect a nonspecific response to excessive overexpression of short RNAs, we generated miR-125b-2 mutants by changing $3 \mathrm{nt}$ in its seed region (Supplemental Fig. S1C). FL MPs transduced with $m i R-125 b-2$ mutants failed to exhibit an increase in the number and size of CFU-MKs (Fig. 2B,C), thus excluding the possibility of a nonspecific response of FL MPs.

Stem cells possess the capacity for unlimited selfrenewal and asymmetric cell division, which distinguishes them from progenitor cells. To investigate the possibility that $m i R-125 b-2$ confers a self-renewal potential to MPs, we performed serial replating assays in methocellulose-based colony-forming assays in the presence of TPO (thrombopoietin) only. Whereas we did not observe CFU-MKs in empty vector-transduced cells in the first replating, miR-125b-2-transduced MPs possessed replating capacity throughout the time of investigation (Fig. 2D). Concomitantly, miR-125b-2-transduced MPs sustained and proliferated in liquid culture in the presence of only TPO for $>30 \mathrm{~d}$, whereas the empty vector control MPs died out after $18 \mathrm{~d}$ (Supplemental Fig. S1D). FL MPs transduced with miR-125b-2 mutants did not show an enhanced replating efficiency (data not shown).
Thus, miR-125b-2 not only increases the proliferation of MPs, it also enhances their ability to self-renew.

As these effects might be species-specific, we tested whether overexpression exerts similar effects in human hematopoietic cells. We retrovirally overexpressed $m i R$ $125 b-2$ in CD $34^{+}$-HSPCs. Similar to findings in murine cells, forced expression of miR-125b-2 markedly increased the formation of larger CFU-MKs without blocking megakaryocytic differentiation (Fig. 2E,F).

To further assess consequences of $m i R-125 b-2$ overexpression on megakaryocytic development, we transduced K562 cells with miR-125b-2. K562 cells, which do not express $m i R-125 b$ (Supplemental Fig. S2A), are multipotent and differentiate along the megakaryocytic lineage upon induction with chemical compounds or genetic alteration (Tetteroo et al. 1984). Forced expression of miR-125b-2 ( 7.8-fold higher levels relative to endogenous $m i R-125 b$ expression of CMK cells) (Supplemental Fig. S2A) led to increased CD61 and reduced glycophorin A (GlyA) expression, indicating the initiation of megakaryocytic differentiation (Fig. 2G). The mRNA expression of megakaryocytic markers was increased, whereas the expression of erythroid markers was decreased (Supplemental Fig. S2B). The proliferation rate of $m i R-125 b-2-$ transduced K562 cells was not markedly altered (data not shown).

Overexpression of miR-125b-2 increases proliferation and self-renewal of MEPS

In comparison with non-DS-AMKL, DS-AMKL and DS-TL represent a unique entity in that their blast cells frequently exhibit features of cells in the erythroid lineage. Since megakaryocytic and erythroid cells arise from a common precursor (MEP), DS-AMKL/TL may be originated from MEPs. To analyze a possible effect of $m i R-125 b-2$ on MEPs and the erythroid lineage, we performed serial replating assays of wild-type FL progenitors in the presence of TPO along with EPO (erythropoietin), SCF (stem cell factor), IL-3 (interleukin-3), and IL-6 (interleukin-6), which support erythroid burst-forming units (BFU-E) and other CFUs of FL cells. In the third replating, whereas $m i R-125 b$-2-transduced FL progenitors mainly formed CFU-MKs $(66.4 \pm 2.8 \%$; or better described as CFU-MK/Es, since many of these CFUMK colonies also contained hemoglobinized erythroid cells) (Fig. 2H,I), a fraction of all colonies were BFU-Es (17.5 \pm $4.2 \%$ ) (Fig. $2 \mathrm{H}, \mathrm{I})$. In contrast, the empty vector-transduced control cells failed to form CFU-MKs or BFU-Es. They exclusively formed CFUs of other lineages (CFU-other), mainly CFUs containing mast cells (CFU-mast) (Fig. 2H,I). Concomitant with this observation, by fluorescence-activated cell sorting (FACS) analysis, we found $\sim 39 \%$ of all cells from the third replating plate were immunophenotypically CD $41^{+} \mathrm{CD} 71^{+}$(compared with $\sim 0.3 \%$ from the control plate), and $\sim 30 \%$ were $\mathrm{CD} 41^{-} \mathrm{CD}^{+} 1^{+}$(erythroid precursors; control: $\sim 0.3 \%$ ) (Fig. 2J).

The observed BFU-Es might have originated from unipotent erythroid progenitors and not from MEPs. However, we did not observe individual BFU-Es in the first and second rounds of replating. Instead, we observed 
A

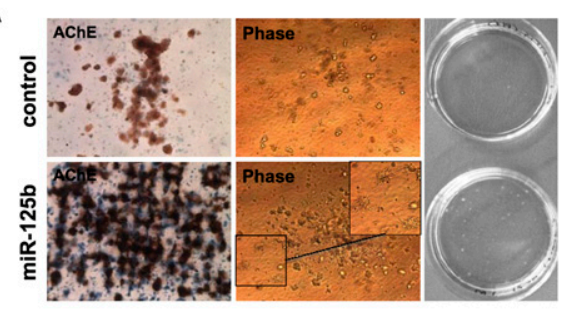

D

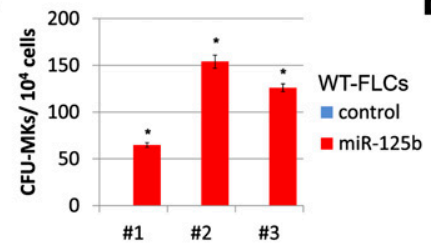

H

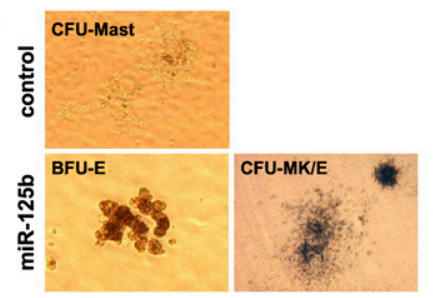

B

\section{E}

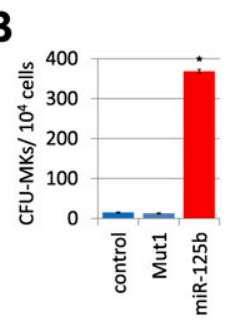

F
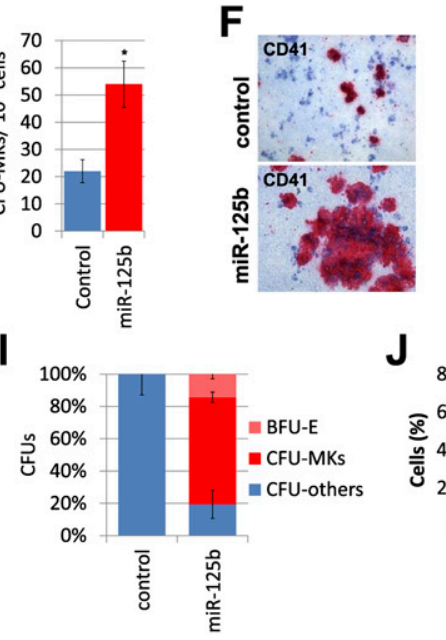

C

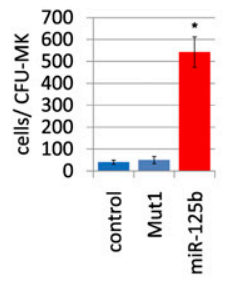

G
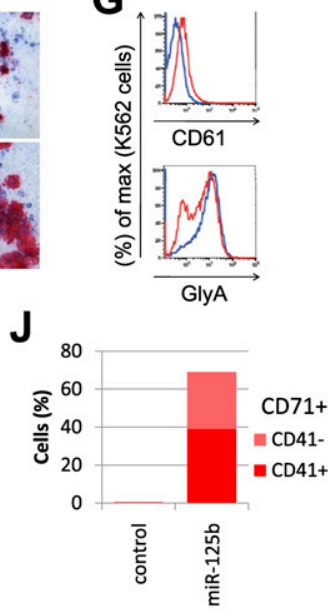

Figure 2. miR-125b-2 overexpression induced proliferation and differentiation of MPs and MEPs. (A) Microscopic (left, middle) and macroscopic (right) images of AChE-stained and unstained (Phase) CFU-MKs from miR-125b-2-transduced and empty vectortransduced (LMPIG or MSCV-puro) murine FL cells. The inset of the bottom middle panel shows proplatelet formation. Pictures here are representative images from $n=3$ independent experiments. $(B, C)$ Megakaryocytic colony-forming assay of $m i R-125 b-2$ transduced, mutated miR-125b-2-transduced (mut1), and empty vector-transduced (LMPIG; control) wild-type FL MPs using methocellulose-based assays in the presence of $20 \mathrm{ng} / \mathrm{mL}$ TPO. (B) Diagram and statistics showing the number of CFU-MKs per $10^{4}$ plated cells. Data of replicates from one of two independent experiments are shown as means \pm SD. $\left({ }^{\star}\right) P<0.05$. $(C)$ Diagram and statistics showing the number of cells per CFU-MK. Data from replicates from one representative experiment are shown as means \pm SD. $\left(^{\star}\right) P<0.05$. $(D)$ Diagram and statistics showing the number of CFU-MKs (per $10^{4}$ plated cells) in serial replating of $m i R-125 b-2-$ transduced and empty vector-transduced (LMPIG; control) wild-type FL progenitors using methocellulose-based assays. Data from replicates from one of two independent experiments are shown as means \pm SD. $\left({ }^{\star}\right) P<0.05$. $(E)$ Diagram and statistics showing the number of CFU-MKs per $10^{4} \mathrm{miR}$-125b-2-transduced and empty vector-transduced (MIGR1; control) human CD34 ${ }^{+}$-HSPCs. Data from $n=2$ independent experiments are shown as means \pm SD. $\left(^{\star}\right) P<0.05 .(F)$ Representative images of immunohistochemically stained (CD41) and hematoxylin and eosin-stained (HE) colony-forming assays as shown in E. (G) CD61 and GlyA expression in miR-125b-2transduced and empty vector-transduced $\mathrm{K} 562$ cells. The representative FACS profiles from one of two independent experiments are shown. (Blue line) Empty vector (LMPIG; control); (red line) miR-125b-2. (H) Representative microscopic images showing unstained (Phase) CFUs (CFU-Mast, BFU-E, and CFU-MK/E) from miR-125b-2-transduced and empty vector-transduced (MSCV-puro; control) murine wild-type FL cells from the third replating using methocellulose-based assays in the presence of TPO, SCF, EPO, IL-3, and IL-6. $(I, J)$ Diagrams showing the relative distribution of CFUs $(I)$ and the percentages of CD $71^{+} \mathrm{CD} 41^{-}$and CD $71^{+} \mathrm{CD} 41^{+}$cells $(J)$ as assessed by flow cytometry in the third replating of miR-125b-2-transduced and empty vector-transduced (MSCV-puro) murine wild-type FL cells as shown in $H$.

many large CFU-MKs with hemoglobinized erythroid cells (data not shown). Thus, these data argue that $m i R$ 125b-2 can expand early hematopoietic progenitor cells (i.e., MEPs) with the potential to differentiate along the megakaryocytic and erythroid lineages without affecting their differentiation.

\section{Overexpression of miR-125b-2 cooperates with Gatals mutation}

GATA1s mutations are consistently present in leukemic blasts of children with DS-AMKL and DS-TL. In the knock-in mouse model, Gata1s increases the proliferation of FL MPs in vitro and in vivo (Li et al. 2005). To test a potential synergistic function of Gata1s and miR$125 b-2$, we transduced Gata1s mutant FL cells with miR-125b-2 or the empty vector control and performed serial replating assays. Consistent with previous results (Li et al. 2005), we observed an increase in the number and size of CFU-MKs from Gata1s mutant FL progenitors (empty vector-transduced) and an enhanced replating efficiency in comparison with their wild-type counterparts (Fig. 3A; Supplemental Fig. S3). Strikingly, miR125b-2-transduced Gata1s FL progenitors frequently 
A

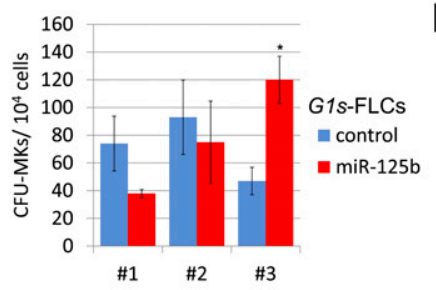

D

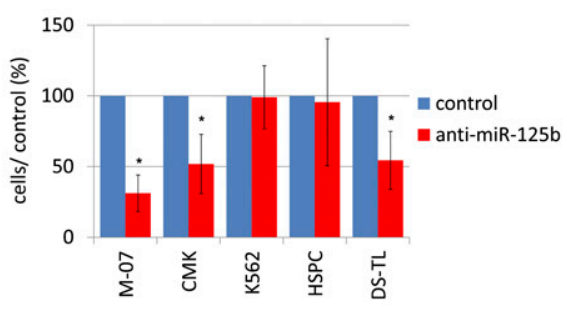

B
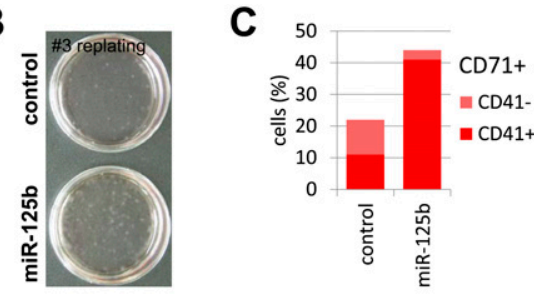

E

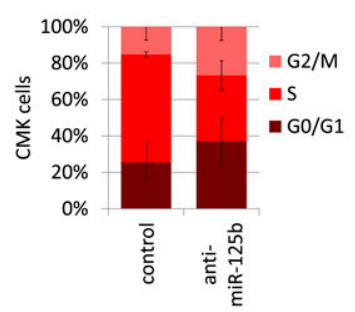

Figure 3. $m i R-125 b-2$ overexpression synergizes with Gata1s mutation, whereas miR-125b repression inhibits DS megakaryocytic leukemia cell growth. (A) Diagram and statistics showing the number of CFU-MKs (per $10^{4}$ plated cells) in serial replating of miR-125b-2-transduced and empty vector-transduced (MSCV-puro; control) Gata1s FL cells (G1s-FLCs) using methocellulose-based assays in the presence of TPO, SCF, EPO, IL-3, and IL-6. Data from replicates in one representative experiment are presented as means \pm SD. $\left(^{\star}\right) P<0.05$. (B) Macroscopic images of the colony-forming assays from the third replating as shown in $A$ and $C$. (C) Flow cytometric analysis of the third replating of miR-125b-2-transduced and empty vector-transduced (control) murine Gata1s FL cells. The diagram shows percentages of $\mathrm{CD} 71^{+} \mathrm{CD} 41^{-}$and $\mathrm{CD} 71^{+} \mathrm{CD} 41^{+}$cells. (D) Cell counts of M-07 $(n=4)$, CMK $(n=4)$, and K562 cell lines $(n=4)$, as well as CD $34^{+}$-HSPCs $(n=3)$ and primary DS-TL blasts $(n=3) 48 \mathrm{~h}$ after transfection with anti-miR-125b, in relation to the nonsilencing oligonucleotide-transfected cells as a control. Data from independent experiments are shown as means \pm SD. $\left({ }^{\star}\right) P<0.05$. $(E)$ Cell cycle analysis using 7-AAD and $\mathrm{BrdU}$ of CMK cells $48 \mathrm{~h}$ after transfection with anti-miR-125b or nonsilencing oligonucleotides. The diagram shows the percentage of cells in G0/G1, S, and G2/M phase. Data from $n=2$ independent experiments are shown as means \pm SD.

formed larger CFU-MKs than Gata1s-only CFU-MKs throughout the serial replating experiment (Supplemental Fig. S3). In addition, the number of CFU-MKs from miR-125b-2-transduced Gata1s FL progenitors increased constantly in each replating and was significantly higher in the third replating in comparison with the empty vector-transduced Gata1s cells (Fig. 3A,B), suggesting a synergy of Gata1s and miR-125b-2 to further enhance proliferation and self-renewal of FL MPs. Consistent with this, we also observed increased proportions of $\mathrm{CD} 41^{+}$ and $\mathrm{CD} 71^{+}$cells in replating plates with miR-125b-2transduced Gata1s FL progenitors in comparison with empty vector-transduced control cells (Fig. 3C). In addition, we did not observe BFU-E colonies emerging from replating assays from miR-125b-2-transduced Gata1s FL progenitors in comparison with miR-125b-2-transduced wild-type FL progenitors (data not shown). This is expected, since Gata1s mutation impairs fetal erythropoiesis, as we demonstrated previously in Gata1s knock-in mice (Li et al. 2005).

\section{Down-regulation of miR-125b in DS megakaryocytic} leukemia cells inhibits their proliferation

To test dependency of proliferation of megakaryoblastic leukemia cells on continuous expression of miR-125b, we transfected CMK (DS-AMKL) and M-07 (non-DS-AMKL) cell lines with chemically modified oligonucleotides complementary to the sequence of $m i R-125 b$ (anti-miR$125 b$ ). miR-125b is highly expressed in both cell lines, as confirmed by Northern blot and quantitative RT-PCR (qRT-PCR), whereas expression of miR-125b is nearly undetectable in the presence of anti-miR-125b (Supplemental Figs. S2A, S4A). The number of viable cells was reduced upon transfection of anti-miR-125b in comparison with cells transfected with a nonsilencing control oligonucleotide (Fig. 3D). In contrast, K562 cells, which do not express miR-125b, did not show a similar response (Fig. 3D; Supplemental Fig. S2A). The effect was caused mainly by reduced proliferation, as indicated by cell cycle analysis with less $\mathrm{BrdU}^{+}$cells in $\mathrm{S}$ phase (Fig. 3E; Supplemental Fig. S4B,C). To investigate this effect in primary human cells, we transfected DS-TL leukemic blasts and CD $34^{+}-$HSPCs with anti-miR-125b. Similar to the cell lines, DS-TL leukemic blasts ceased to proliferate (Fig. 3D); in contrast, the number of CD34 $4^{+}$-HSPCs, which express only low levels of miR-125b in comparison with DS-TL leukemic blasts (Fig. 1B), was not altered significantly (Fig. 3D).

In conclusion, proliferation of DS-AMKL cell lines and primary DS-TL leukemic blasts is dependent on expression of $m i R-125 b$, and the hyperproliferative phenotype can be reverted upon down-regulation of miR-125b.

\section{miR-125b-2 perturbs myeloid differentiation of HSPCs}

miR-125b-2 overexpression increases the proliferation of MEPs and is required for growth of DS-AMKL cell lines, as well as primary DS-TL blasts. To investigate a broader role of miR-125b-2 in hematopoiesis, we transduced HSPC-enriched mononuclear cells from the bone marrow (BM) of adult mice. The number of CFUs of the miR125b-2-transduced BM cells exceeded the number of the control CFUs (Fig. 4A). Three major types of CFUs were present in the miR-125b-2-transduced BM cells: two types of large CFUs (type 1A and 1B), and one type of medium-sized, compact clusters (type 2) (Fig. 4B), as described previously for MLL-AF9-transduced myeloid cells (Johnson et al. 2003). We picked individual CFUs from each type and analyzed their cell composition by cytospin and flow cytometry (FACS). Type 1A CFUs contained mainly Mac-1 ${ }^{\text {high }}$ macrophages and type 1B 

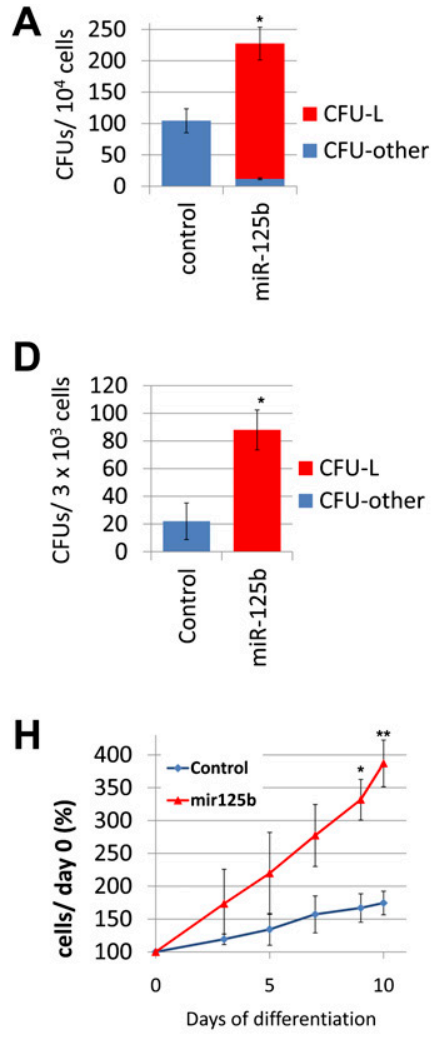

B

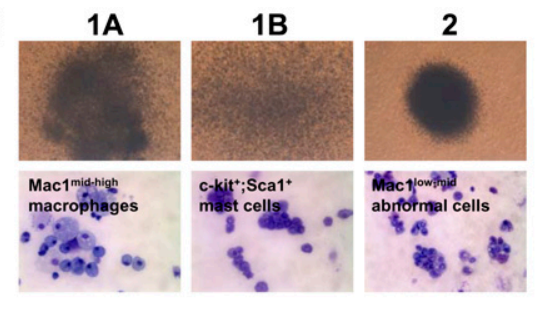

E

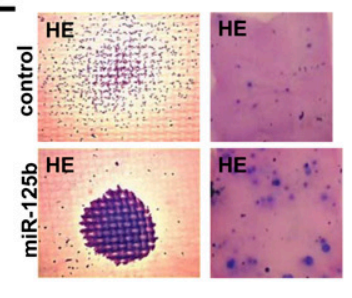

$\mathbf{F}$
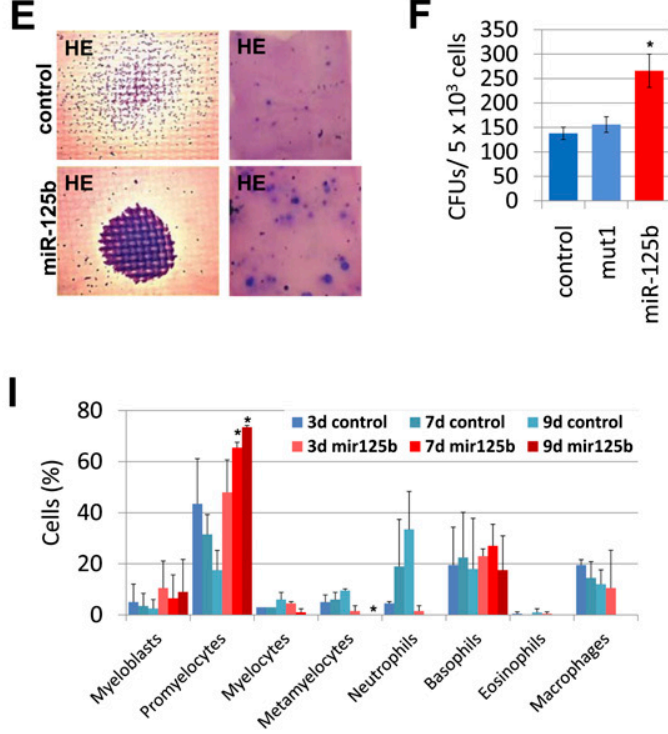
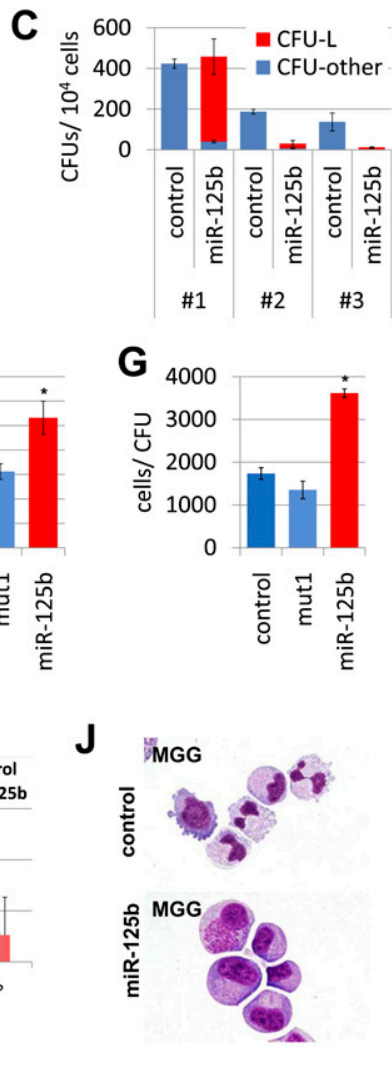

Figure 4. Overexpression of $m i R-125 b-2$ perturbs myeloid differentiation of HSPCs. $(A)$ Number of CFUs per $10^{4}$ plated $m i R-125 b-2$ transduced and empty vector-transduced $(L M P I G)$ murine BM cells. Data of replicates from one of three independent experiments are presented as means $\pm \mathrm{SD} .\left(^{*}\right) P<0.05$. $(B)$ Microscopic images of colony-forming assays show representative CFUs from one of $n=3$ independent experiments of miR-125b-2-transduced murine BM cells. The bottom panel shows May-Grünwald-Giemsa (MGG)-stained cytospins and the immunophenotype of the respective colonies. Type 1A CFUs contained Mac- $1^{\text {high }}$ macrophages and type $1 \mathrm{~B}$ CFUs contained mast cells (CFU-others). Type 2 CFUs contained a mixture of granulocytes, macrophages, and immature myeloblasts (CFUL). (C) Diagram showing the number of CFUs (per $10^{4}$ plated cells) in serial replating of miR-125b-2-transduced and empty vectortransduced (MSCV-puro; control) BM cells using methocellulose-based assays. Error bars represent means \pm SD of replicates in one representative experiment. (D) Number of CFUs per $3 \times 10^{3}$ plated miR-125b-2-transduced and empty vector-transduced (MIGR1; control) human CD34 ${ }^{+}$-HSPCs using collagen-based colony-forming assays. Data from $n=3$ independent experiments are shown as means $\pm \mathrm{SD} .\left(^{*}\right) P<0.05$. (E) Representative images of hematoxylin and eosin $(\mathrm{HE})$-stained colony-forming assays from miR-125b-2transduced and empty vector-transduced (MIGR1; control) human CD34+-HSPCs as shown in D. The left panel shows microscopic images and the right panel shows the colony-forming assay without magnification. $(F, G)$ Colony-forming assays of $m i R-125 b$-2transduced, mutated miR-125b-2-transduced (mut1), and empty vector-transduced (LMPIG; control) human CD34 ${ }^{+}$-HSPCs using methocellulose-based assays. $(F)$ Diagram and statistics showing the number of CFUs per $5 \times 10^{3}$ plated cells. (G) Diagram and statistics showing the number of cells per CFU. Replicates from one representative experiment are shown as means \pm SD. $\left(^{\star}\right) P<0.05$. $(H-J)$ Cell counts (in relation to day $0 ;=100 \%)(H)$, differential WBC counts $(I)$, and May-Grünwald-Giemsa-stained cytospins (day 9) (J) of $\mathrm{miR}$-125b-2-transduced and empty vector-transduced (control) human CD34 ${ }^{+}$-HSPCs cultured in granulocytic differentiation medium. Data from $n=3(H)$ and $n=2(I)$ independent experiments are shown as means \pm SD. $\left(^{\star}\right) P<0.05 ;\left(^{\star \star}\right) P<0.01$.

CFUs contained mast cells (CFU-other) (Fig. 4A,B). The vast majority of the CFUs (type 2) displayed a unique colony morphology and contained a mixture of granulocytes, macrophages, and immature myeloblasts (CFU-L) (Fig. 4A,B). Cells in these colonies were largely Mac- $1^{\text {low/mid }}$, whereas $10 \%$ of cells also expressed Gr- 1 . The cells stained negative for other markers, such as Ter-119, Sca-1, c-kit, CD3, and B220 (data not shown).

In FL MPs/MEPs, enforced miR-125b-2 expression led to increased self-renewal with enhanced replating efficiency. To investigate the self-renewal capacity in $m i R$ 125b-2-transduced BM HSPCs, we performed serial replating assays. In contrast to MPs/MEPs, the number of CFUs from miR-125b-2-transduced BM HSPCs decreased significantly after the first replating (Fig. 4C). These data indicate that overexpression of $m i R-125 b-2$ specifically increases the self-renewal capacity of FL MPs and MEPs, but not the adult BM HSPCs.

To test if high levels of $m i R-125 b-2$ perturb human myelopoiesis, we retrovirally overexpressed $\mathrm{miR}-125 \mathrm{~b}-2$ in CD34+-HSPCs. In colony-forming assays, we observed a marked increase in the number and size of CFUs upon miR-125b-2 transduction in comparison with empty vector- and mutated $m i R-125 b$-2-transduced control cells 
(Fig. 4D-G). Colonies exhibited unique, abnormal morphology, and contained a mixture of immature cells (CFU-L) (Fig. 4E).

During granulocytic differentiation, immature myeloblasts differentiate through the stages of promyelocytes, myelocytes, and metamyelocytes to become granulocytes in the presence of granulocyte colony-stimulating factor (G-CSF). As expected, when we cultured empty vector-transduced CD $34^{+}$-HSPCs in granulocytic differentiation medium, we observed a gradual reduction of immature promyelocytes and an increase of more mature granulocytic cells (myelocytes, metamyelocytes, and granulocytes) with time in culture. In contrast, forced expression of $m i R-125 b-2$ led to a 2.2 -fold increase of the absolute number of cells in the culture (Fig. 4H), accompanied by an increase of the proportion of promyelocytes, whereas mature neutrophils and macrophages were greatly underrepresented, as assessed by differential white blood cell (WBC) counts (Fig. 4I,J). Only basophils were seen in the culture (Fig. 4I). Consistent with these data, we observed an increase of $\mathrm{CD}_{3} 3^{+}$promyelocytes upon forced $m i R-125 b$-2 expression, whereas the mature granulocytes in the control were CD33- (Supplemental Fig. S5A). Consistent with those data obtained in murine BM-HSPCs, the replating efficiency was not increased in human CD34 $4^{+}$-HSPCs (Supplemental Fig. S5B). Neither the myeloid differentiation block nor the increased proliferation of CD34 ${ }^{+}$-HSPCs could be observed upon forced expression of $m i R-125 b-2$, mutated in the seed region, validating the specificity of the observed effects of $m i R$ 125b-2 (Supplemental Fig. S5C-F).

These data indicate that $m i R-125 b-2$ overexpression in HSPCs enhances their proliferation and blocks myeloid differentiation at the promyelocyte stage without enhancing replating efficiency.

\section{Identification of miR-125b target genes in hematopoietic cells by integrative bioinformatic analysis}

To identify target mRNAs of miR-125b in the hematopoietic system, we performed integrative bioinformatic analysis. We performed global microarray gene expression profiling of $m i R$-125b-2-overexpressing HSPCs ( $m i R$ $125 b$-2 vs. empty vector), as well as $m i R-125 b$ knockdown AMKL cell lines (anti-miR-125b vs. control). We reasoned that target genes of $m i R-125 b$ would carry a miR-125b-binding site in the 3'UTR (untranslated region) (predicted by TargetScan) (Lewis et al. 2005; Grimson et al. 2007), and would be inversely regulated after overexpression or repression of $m i R-125 b$. Using dChip software (Li and Wong 2001), we identified 56 probes, representing 53 genes, among the putative $m i R$ $125 b$ target gene list (as predicted by TargetScan). These genes were up-regulated in the AMKL cell lines upon $m i R-125 b$ knockdown and down-regulated in HSPC upon miR-125b-2 overexpression (Fig. 5A; Supplemental Fig. S6). The most represented Gene Ontology categories of the 53 target genes, as indicated by the DAVID bioinformatics database (Dennis et al. 2003), include RNA
A

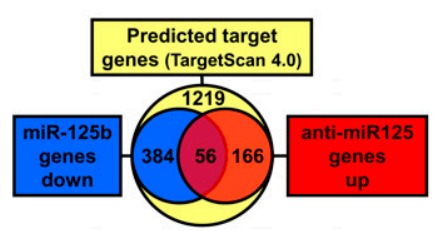

B

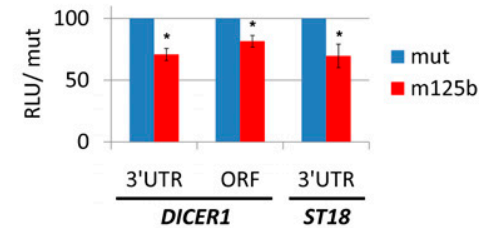

C
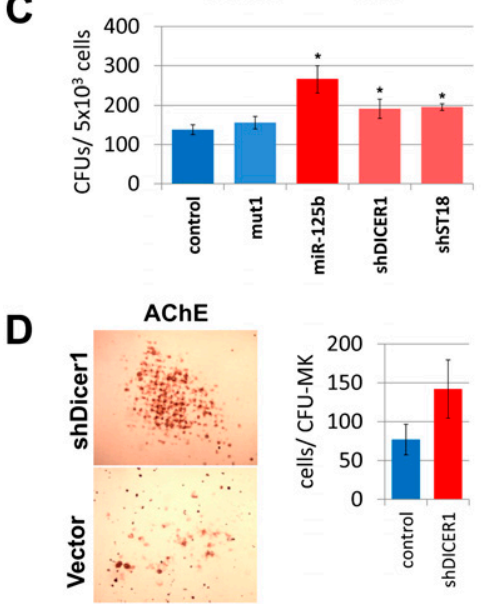

Figure 5. Integrative bioinformatic analysis identified miR$125 \mathrm{~b}$ target genes in hematopoietic cells. (A) Venn-diagram showing the number of probes (Affymetrix HG U133 plus 2.0) for genes predicted as target genes by TargetScan 4.1, upregulated $>1.2$-fold upon transfection of anti-miR-125b in M-07 $(n=2)$ and CMK $(n=2)$ cells in comparison with the nonsilencing control ( $n=2$, respectively), and down-regulated $>1.2$-fold upon transduction of HSPCs with miR-125b-2 in comparison with empty vector-transduced control cells (MIGR1). (B) Dual -uciferase reporter assay of HEK293T cells cotransfected with Luc-DICER1-ORF, Luc-DICER1-3'UTR, or Luc-ST183'UTR, together with MIGR1-miR-125b-2 or MIGR1-mut. Relative light units (RLUs) are presented as means \pm SD of $n=3$ independent experiments in relation to the control $\left.(=100 \%) .{ }^{*}\right)$ $P<0.05$. $(C)$ Number of CFUs per $5 \times 10^{3}$ plated miR-125b-2transduced, mutated miR-125b-2-transduced, shST18-transduced, shDICER1-transduced, and empty vector-transduced (LMPIG; control) human CD34+-HSPCs. Replicates from one representative experiment are shown as means $\pm \mathrm{SD} .\left({ }^{\star}\right) P<$ 0.05. (D) Colony-forming assays of shDICER1-transduced and empty vector-transduced (LMPIG; control) murine FL cells. (Left) Microscopic AChE-stained images showing representative CFUs. (Right) Diagram showing the number of AChE-positive cells per CFU. Cell counts of five randomly picked colonies from one of three independent experiments are shown as means \pm SD.

binding, cell communication, intracellular signaling cascade, and regulation of biological processes (Supplemental Table S2). The microarray data were confirmed for the candidate target genes DICER1 and ST18 (suppression of tumorigenicity 18) by qRT-PCR (Supplemental Fig. $\mathrm{S} 7 \mathrm{~A})$. The knockdown of DICER1 upon overexpression 
of miR-125b-2 in K562 cells was validated further by Western blot (Supplemental Fig. S7B).

We next sought to verify a direct regulation of these two target genes by $m i R-125 b-2$ using a luciferase reporter assay. ST18 has one predicted target site in the $3^{\prime} \mathrm{UTR}$, and DICER1 has one site in the $3^{\prime} \mathrm{UTR}$ and one conserved site ( 17 genomes) within the ORF, as described previously (Forman et al. 2008). We subcloned the $3^{\prime}$ UTRs and the ORF containing the miR-125b-binding site of these transcripts into the luciferase-based reporter vector ( $p M I R-R E P O R T)$ and cotransfected the reporter constructs in the HEK293T cells with pMIGR1-mut (mutated miR-125b-2) or pMIGR1-miR-125b-2. miR-125b-2 expression repressed the relative luciferase activity of reporter constructs containing ST18 3'UTR, DICER1 $3^{\prime}$ UTR, and DICER1 ORF (Fig. 5B) in comparison with the mutated miR-125b-2. This shows that both ST18 and DICER1 are direct targets of miR-125b-2.

RNAi-mediated knockdown of miR-125b target genes DICER 1 and ST18 recapitulates the hyperproliferative effect of miR-125b-2

We investigated further whether the phenotypes elicited upon overexpression or reduction of miR-125b levels might be reproduced by modulating expression of its target genes. The association of reduced DICER1 and ST18 expression levels and cancer has been described previously (Jandrig et al. 2004; Karube et al. 2005; Kumar et al. 2009). We transduced human CD34+-HSPCs with a retrovirus (LMPIG) expressing shRNAs directed to DICER1 (shDICER) or ST18 (shST18), and confirmed knockdown by qRT-PCR (data not shown). Repression of DICER1 or ST18 increases the number of CFUs by 1.4-fold (Fig. 5C). The results were validated using two (ST18) and three (DICER1) different shRNAs, excluding the possibility of off-target effects (Supplemental Fig. $\mathrm{S7C}$. In accordance with these data, when we repressed Dicer1 expression in mouse FL cells with a MSCV-based retrovirus expressing shRNA directed to Dicer1, we observed hyperproliferative, AChE-positive CFU-MKs in the colony-forming assay (Fig. 5D; Supplemental Fig. S7D).

Thus, we show by integrative analysis of the transcriptome of hematopoietic cells that miR-125b-2 may exert its proproliferative effect on hematopoietic progenitor cells by repression of DICER1 expression and by inhibiting the tumor suppressor ST18.

\section{miR-125b target genes are repressed in DS-AMKL} and DS-TL

To determine if the above-identified target genes of miR$125 \mathrm{~b}$ are down-regulated in primary leukemic blasts highly expressing miR-125b, we analyzed the global gene expression profiles of patient samples for which both $m i R$ $125 b$ expression data and microarray gene expression data were available. Pearson's correlation within the Gene Set Enrichment Analysis (GSEA) (Subramanian et al. 2005) was used to determine the degree of linear relationship between $m i R-125 b$ expression and the expression of the identified miR-125b target gene set. We confirmed the negative relationship, and therefore down-regulation of the curated target genes set of miR-125b in samples highly expressing miR-125b (Fig. 6A). To validate our findings, we performed GSEA using an independent, previously published data set that includes 23 patients with the DSAMKL and 37 patients with non-DS-AMKL (Bourquin et al. 2006). Similarly, we observed negative enrichment of the curated miR-125b target gene set in patients with DSAMKL in comparison with those with non-DS-AMKL (Fig. 6B). Of note was the fact that the genes DICER1 and ST18 were among the leading edge subsets (Fig. 6A,B).

Thus, our data show that miR-125b is highly expressed in DS-AMKL, whereas its putative target genes are downregulated in DS-AMKL samples. These findings support a potential role of $m i R-125 b-2$ in the pathogenesis of DSAMKL.

\section{Discussion}

We demonstrated that an Hsa21-encoded miRNA, miR125b-2, plays a pivotal role in megakaryopoiesis by increasing proliferation and self-renewal of MPs and MEPs without affecting their differentiation. Our functional genetic studies further indicate that miR-125b-2 overexpression perturbs myeloid differentiation. In authentic human DS-AMKL, miR-125b-2 is highly overexpressed. In line with the observed impairment of proliferation of the DS-AMKL cell line and primary DS-TL blasts upon knockdown of miR-125b, and the demonstration of synergism between miR-125b-2 overexpression and Gata1s mutation in FL progenitors, our data indicate that miR-125b-2 is a potential oncomiR involved in the pathogenesis of trisomy 21-associated megakaryoblastic leukemia. Using an integrative bioinformatic approach, we analyzed the transcriptome after experimental alteration of miR-125b expression levels, and defined a set of target genes of $m i R-125 b$ in hematopoietic cells that were down-regulated in DS-AMKL patient samples. The multidisciplinary approach we took underscores the validity of our findings and their biological relevance.

Interestingly, human Hsa21 carries several genesincluding RUNX1,ERG, ETS2, and GABPA - that encode transcription factors serving as key regulators of megakaryocyte development (Elagib et al. 2003; Rainis et al. 2005; Pang et al. 2006). It was shown recently that overexpression of ERG and ETS2 promoted megakaryopoiesis and synergized with GATA1 mutations (Gata1s or Gata1 knockdown) to immortalize fetal progenitors in vitro (Salek-Ardakani et al. 2009; Stankiewicz and Crispino 2009). However, none of these genes is overexpressed in DS-AMKL and DS-TL samples in comparison with non-DS-AMKL samples (Bourquin et al. 2006). Thus, it is uncertain whether the in vitro synergy between $E R G$ or ETS2 overexpression and GATA1s mutation is directly relevant to the pathogenesis of DS-TL and DS-AMKL in vivo. Here we show that miR-125b-2 is another "megakaryocyte gene" on Hsa21 encoding for a different class of developmental regulators: miRNAs. In contrast to $E R G$ and ETS2, miR-125b is indeed highly overexpressed in DS-AMKL and DS-TL blasts, whereas its expression is 


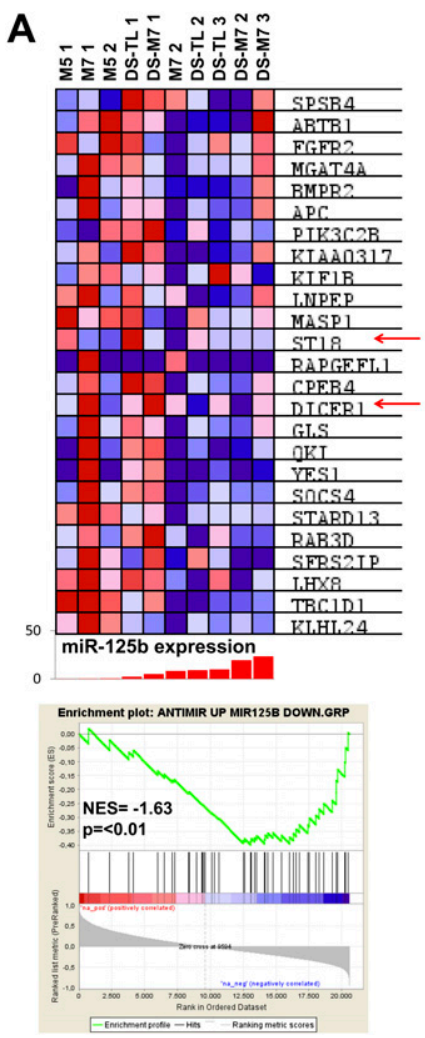

B
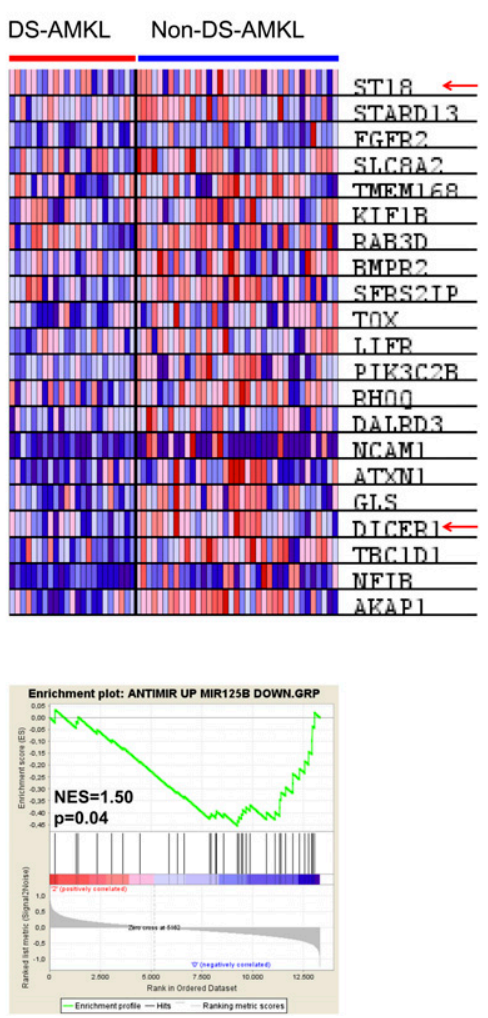

Figure 6. $m i R-125 b$ target genes are down-regulated in DS-AMKL. (A) GSEA of the identified miR-125b target gene set in leukemic blasts from patients with DS-AMKL (DS-M7, $n=3)$, DS-TL $(n=3)$, non-DSAMKL (M7, $n=2)$, and AML FAB M5 (M5, $n=2)$. Pearson's correlation was used to determine the degree of linear relationship between miR-125b expression and the expression of the identified $m i R-125 b$ target gene set. (Top) Heat map of the leading-edge subset including DICER1 and ST18 (arrows), with the miR$125 \mathrm{~b}$ expression below. Samples are ordered according to their miR-125b expression. Normalized enrichment score $(\mathrm{NES})=-1.63$; false discovery rate (FDR) $q=$ $0.007 ; P=0.007$. (B) GSEA of the identified miR-125b target gene set in leukemic blasts from patients with DS-AMKL (DS-M7, $n=23$ ) and non-DS-AMKL (M7, $n=37$ ) from a previously published data set (Bourquin et al. 2006). (Top) Heat map of the leading-edge subset including DICER1 and ST18 (arrows). (Bottom) Enrichment plot and statistics. NES $=-1.50 ;$ FDR $q=$ $0.042 ; P=0.042$. low in CD34 ${ }^{+}$-HSPCs, normal megakaryocytes, and AML FAB M5. Its overexpression appears closely associated with AMKL (especially with DS-AMKL/TL), and not with AML in general or with megakaryocytic differentiation. In fact, by miRNA profiling, it was shown that miR-125b was expressed in human MEPs, but was down-regulated during megakaryocyte differentiation (Lu et al. 2008). Consistent with this, we observed dramatic expansion of MEPs in response to miR-125b-2 overexpression, indicating a potential role of this miRNA in controlling proliferation of MEPs. More importantly, we also observed synergy between overexpression of miR-125b-2 and Gata1s mutation to further increase proliferation and self-renewal of fetal MPs and MEPs (presumed cells of origin for DS-AMKL/TL), indicating potentially direct involvement of this miRNA in the pathogenesis of DSAMKL/TL. Currently, factors leading to overexpression of miR-125b, particularly in DS-AMKL/TL blasts, remain to be defined. It will also be of great interest to determine whether miR-125b is overexpressed in human DS FL cells in the absence of GATA1s mutation, as FLs of healthy fetuses with DS have already contained hematopoietic progenitors preferentially differentiating toward megakaryocytic and erythroid lineages (Chou et al. 2008; Tunstall-Pedoe et al. 2008).

In mouse mesenchymal stem cells, exogenous miR$125 b$ expression reduced proliferation and mediated differentiation (Mizuno et al. 2008), indicating a cell context-dependent role of $m i R-125 b$, inducing a proliferation program in one cell type and repressing a proproliferative program in another. The cell context-dependent difference of the effect of miR-125b is underscored by previous studies in prostate cancer cell lines. Despite the observation that down-regulation of miR-125b in AMKL cell lines and prostate cancer cell lines results in a proliferation arrest (Lee et al. 2005), the mechanism differs between cell types. The stimulation of androgen-independent growth of prostate cancer cells by $m i R-125 \mathrm{~b}$ is at least partially mediated by down-regulation of $B A K 1$, and thereby inhibition of apoptosis (Shi et al. 2007). For AMKL cell lines, we failed to detect repression of BAK1 (data not shown). Also, the recently defined target tumor suppressor p53 is not among our list of target genes (Le et al. 2009). This argues for a differential gene expression program involved in crucial biological processes regulated by $m i R-125 b$.

Previous studies showed that both human and mouse cancers are characterized by a global reduction of mature miRNA levels compared with normal tissues (Lu et al. 2005; Kumar et al. 2007). We identified and experimentally validated DICER 1 as a direct target of miR-125b. Our results indicate a regulatory negative feedback loop between DICER1 and miR-125b-2. Production of mature miR-125b by DICER1 results in repression of DICER 1 expression levels and, consequently, impaired overall miRNA processing (Fig. 7). Therefore, we propose a miRNA-mediated mechanism for low DICER1 expression levels, and provide an explanation for the observed failure to express mature miRNAs in many cancers. In concert with those data, we observed a global reduction of 


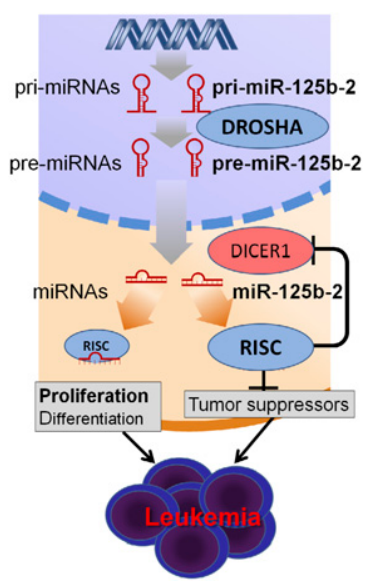

Figure 7. Proposed model for the role of Hsa21-encoded miR$125 b-2$ in leukemogenesis. DICER1 and miR-125b-2 form a regulatory negative feedback loop. Production of mature miR-125b-2 by DICER 1 results in repression of DICER 1 expression levels and, subsequently, impaired overall miRNA processing. This miRNA-mediated mechanism for low DICER1 expression levels leads to a failure to express mature miRNAs essential for terminal hematopoietic differentiation. These prooncogenic effects of $m i R-125 \mathrm{~b}-2$ can be enhanced further by the repression of tumor suppressors such as ST18.

miRNA expression in DS-AMKL samples highly expressing $m i R-125 b$ (K Böhmer and D Reinhardt, unpubl.). Recently, DICER1 post-transcriptional regulation that affects overall miRNA expression has been shown for let-7 (Tokumaru et al. 2008). Let-7c resides proximal of miR-125b-2 on Hsa21, implicating that both miRNAs may coordinately regulate DICER 1 expression. The oncogenic properties of this function of $m i R-125 b-2$ are underscored by recently published observations that impaired miRNA biogenesis and Dicer1 haploinsufficiency accelerates oncogenic transformation and oncogenesis of human cells and mouse models through the deregulation of target oncogenes (Kumar et al. 2007, 2009). Our study suggests a mechanism of tumor propagation and regulation of differentiation by miRNAs. Similar to embryonic stem cells (Viswanathan et al. 2008), post-transcriptional blockage of miRNA processing could perturb miRNA-mediated differentiation of HSPCs and promote development of leukemia.

These pro-oncogenic effects of $m i R-125 b-2$ may be further enhanced by repression of tumor suppressors such as ST18. ST18, which is encoded in a frequently imbalanced region of chromosome $8 \mathrm{q} 11$, was first identified as a breast cancer tumor suppressor gene (Jandrig et al. 2004). This zinc finger DNA-binding protein acts as a transcriptional regulator. In breast cancer cell lines and in $\sim 80 \%$ of primary breast tumors, ST18 mRNA is down-regulated, partially by epigenetic mechanisms, such as hypermethylation of the promoter region. Ectopic expression of ST18 in MCF-7 breast cancer cells inhibits colony formation as well as the formation of tumors in a xenograft mouse model (Jandrig et al. 2004). Fibroblasts overexpressing ST18 exhibit increased apoptosis and in- creased expression of tumor necrosis factor- $\alpha$ (TNF- $\alpha$ ) and TNF-induced proapoptotic and proinflammatory genes (Yang et al. 2008).

In conclusion, we showed that $m i R-125 b-2$ is an oncogene potentially involved in the pathogenesis of trisomy 21-associated leukemia. Our finding raises the possibility that up-regulation of this miRNA-either in response to, or together with, modest (1.5-fold) overexpression of other Hsa21-encoded "megakaryocyte genes" such as ERG, ETS2, RUNX1, or GABPA-may confer the leukemia-predisposing effects of Hsa21 to the megakaryocytic lineage by inducing proliferation and self-renewal of MPs and MEPs, while blocking differentiation of other lineages. Consistent with the finding of translocations involving the $m i R-125 b-2$ homolog $m i R$ 125b-1 in pre-B-ALL and MDS (Sonoki et al. 2005; Bousquet et al. 2008), our findings suggest a cell typespecific role of $m i R-125 b$ in hematopoietic cells. We propose that $m i R-125 b-2$ exerts its effect by at least two different mechanisms: inhibition of post-transcriptional miRNA processing by repressing DICER1, and downregulation of tumor suppressor genes such as ST18.

\section{Materials and methods}

\section{Patient samples}

BM specimens from patients with non-DS-AMKL, DS-AMKL, DS-TL, or AML FAB M5, or from healthy donors were obtained from different children, and were provided by the collaborative AML-"Berlin-Frankfurt-Münster" Study Group (AML-BFM-SG, Münster, Germany). The study group performed a central review of the diagnosis, classification, and clinical follow-up of the patients. Mobilized CD34 ${ }^{+}$-HSPCs from donors were positively selected by immunomagnetic labeling with corresponding magnetic cell-sorting beads (Miltenyi Biotech). All investigations were approved by the institutional review board and Ethics Committee of the Medical School Hannover, and informed consent was obtained according to local laws and regulations.

\section{Mice}

All studies involving mice were approved by the Children's Hospital Boston Institutional Animal Care and Use Committee, and were performed in accordance with the relevant protocols. Gata1s mice were generated as described (Li et al. 2005).

\section{Cell culture and transduction}

All cell lines (CMK, M-07, and K562) were obtained from the German National Resource Center for Biological Material (DSMZ), and were cultured under the recommended conditions. Fetal MPs and BM cells from adult mice were processed, expanded, and infected as published previously (Li et al. 2005). Culture, transduction on RetroNectin-coated (Takara) plates, and in vitro differentiation of CD34 ${ }^{+}$-HSPC cells was performed as described (Klein et al. 2007; Skokowa et al. 2009). The mouse stem cell virus (pMSCV)-based pMSCV-puro (Clontech), pMIGR1 (Pui et al. 1999), pMSCV-Puro-IRES-GFP (pLPIG), and $p M S C V$-Puro-IRES-GFP containing the miR-30 backbone ( $p L M P I G$ ) vectors were used. Both $p L P I G$ and $p L M P I G$ retroviral vectors (Dickins et al. 2005) were generous gifts from Dr. Scott Lowe. $p G I P Z$ vectors containing the shRNA sequence directed 
to DICER1 and ST18 were obtained from OpenBiosystems, and were cloned into the $p L M P I G$ vector. Retroviral and lentiviral supernatant was prepared using standard protocols. Detailed procedures and vector design are provided in Supplemental Material.

\section{Flow cytometry and cell sorting}

Standard protocols were followed. Detailed procedures and antibodies are provided in Supplemental Material.

\section{Colony-forming assays}

Murine FL cells were plated in the MegaCult-C collagen-based system (StemCell Technologies) with TPO $\left(5 \mathrm{ng} \mathrm{mL}^{-1}\right)$ and were stained for AChE activity in accordance with the manufacturer's instructions, or in Methocult M3231 methylcellulose medium (StemCell Technologies) in the presence of TPO $\left(20 \mathrm{ng} \mathrm{mL}^{-1}\right)$, or in Methocult M3434 methylcellulose medium (StemCell Technologies $)$ in the presence of TPO $\left(20 \mathrm{ng} \mathrm{mL}^{-1}\right)$. BM cells from adult mice were assayed for their colony-forming activity in Methocult M3231 methylcellulose medium (StemCell Technologies) in the presence of erythropoietin (Epo; $3 \mathrm{U} \mathrm{mL}^{-1}$ ), IL-3 $\left(10 \mathrm{ng} \mathrm{mL}^{-1}\right)$, IL-6 $\left(10 \mathrm{ng} \mathrm{mL}^{-1}\right)$, and SCF $\left(50 \mathrm{ng} \mathrm{mL}^{-1}\right)$; or in Methocult M3434 methylcellulose medium (StemCell Technologies). Puromycin $(1 \mu \mathrm{g} / \mathrm{mL})$ was included to select for transduced, puromycin-resistant cells. Human $\mathrm{CD} 34^{+}$or K562 cells were plated in the CollagenCult, MegaCult, or MethoCult \#4434 colony-forming assays in accordance with the manufacturer's instructions (StemCell Technologies). For serial replating, cells from methocellulose-based colony-forming assays were harvested, washed in IMDM, counted, and seeded in the respective colony-forming assays at a density of $1 \times 10^{4}$ to $2 \times 10^{4}$ cells per plate.

\section{Microarray and bioinformatics analysis}

Microarray expression profiles were collected using Affymetrix Human Genome U133 Plus 2.0 chips, and were analyzed using dChip (Li and Wong 2001) and GSEA (Subramanian et al. 2005). For miRNA target gene prediction, we used the TargetScan 4.1 algorithm (Lewis et al. 2005; Grimson et al. 2007). Analysis of Gene Ontology categories was performed using DAVID bioinformatics database (Dennis et al. 2003). All microarray data have been deposited in NCBI's Gene Expression Omnibus (GEO; http://www.ncbi.nlm.nih.gov/geo) with GEO Series accession numbers GSE19680 and GSE19681.

\section{miRNA expression studies}

miRNA expression was measured on a 7900HT Fast Real-Time PCR System using a TaqMan Human MicroRNA Array version 1.0 (Applied Biosystems) in accordance with the manufacturer's instructions. For miRNA Northern blots, total RNA was separated in $15 \%$ polyacrylamide TBE/Urea gel, transferred to GeneScreen Plus transfer membrane (PerkinElmer), and UV-cross-linked in Stratalinker (Stratagene). Anti-miR-125b (Ambion) was labeled by $\gamma_{-}{ }^{32} \mathrm{P}$-ATP using the mirVana miRNA Detection Kit according to the manufacturer's instructions (Ambion) and was used as the probe. Standard procedures were followed for hybridization/washes and detection.

\section{Transfection of 2'-O-methyl antisense oligonucleotides}

2 '-O-methyl antisense oligonucleotides labeled with Cy3 and directed against the mature $m i R-125 b$ were chemically synthesized (BioSpring). Cells $\left(1 \times 10^{6}\right)$ were electroporated $(330 \mathrm{~V}, 10$ msec) in $100 \mu \mathrm{L}$ of medium containing $0.5 \mu \mathrm{g}$ of 2 '-O-methyl antisense oligonucleotides in a 4-mm electroporation cuvette using an EPI 2500 gene pulser (Fischer). Transfected cells were FACS-sorted after $24 \mathrm{~h}$ as described above.

\section{Western blot}

Total cell lysis and Western blotting were performed using standard protocols as described previously (Li et al. 2007). Western blots were probed with the following antibodies: DICER1 (Abcam) and GAPDH (Abcam). Proteins were visualized with ECL (Amersham) according to the manufacturer's protocols.

\section{$q R T-P C R$}

RNA for mRNA qRT-PCR was isolated using the RNeasy Mini Kit (Qiagen). cDNA was synthesized using the High-Capacity cDNA Reverse Transcription Kit (Applied Biosystems). For mRNA qRT-PCR, the QuantiTect SYBR Green PCR kit (Qiagen) was used according to the manufacturer's specifications. For each $25-\mu \mathrm{L}$ reaction mixture, $250 \mathrm{ng}$ of cDNA were used. mRNA expression was normalized against expression of human GAPDH (Qiagen) expression levels. RNA for miRNA qRTPCR was isolated by use of miRVana miRNA Isolation Kit (Ambion). cDNA Synthesis was performed with the TaqMan MicroRNA Reverse Transcription Kit (Applied Biosystems) according to the manufacturer's instructions. miRNA expression was quantified using TaqMan miRNA assays for hsa-miR-125b and RNU44 as the housekeeping gene (Applied Biosystems). Analysis was done on a StepOnePlus (Applied Biosystems) realtime thermal cycler.

\section{Luciferase reporter assay}

For reporter assays, the $3^{\prime} \mathrm{UTR}$ or ORF fragment of the respective mRNAs containing the miR-125b-binding site were cloned from cDNA into $p M I R-R E P O R T$ miRNA Expression Reporter Vector (Ambion). 293T cells $\left(1 \times 10^{4}\right)$ were plated and cotransfected in 96well plates by using FuGENE HD (Roche), according to the manufacturer's protocol, with $6.25 \mathrm{ng}$ of the firefly luciferase report vector, $0.25 \mathrm{ng}$ of the control vector containing renilla luciferase PGL4.7 (Promega), and 50 ng miRNA expression vector (pMIGR1-miR-125b-2 and pMIGR1-mut). Firefly and renilla luciferase activities were measured consecutively by using dualluciferase assays (Promega) $48 \mathrm{~h}$ after the transfection. All experiments were performed in duplicates.

\section{Acknowledgments}

We thank M. Hamblen for general laboratory support, M. Ballmaier for cell sorting, Thanaseelan Pushpanathan and M. Wackerhahn for technical assistance, A. Schambach and C. Baum for providing plasmids and assistance with lentiviral transduction, and $\mathrm{N}$. von Neuhoff for providing support and assistance with protein analyses. Z.L. was a Fellow of the Leukemia and Lymphoma Society and was supported by the K99 Pathway-to-Independence award from NCI. This work was supported by a grant to D.R. and J.-H.K. from the German National Academic Foundation (RE2580/2-1) and the Madelein Schickedanz Foundation, and to S.H.O. from the NIH. S.H.O. is an Investigator of the Howard Hughes Medical Institute.

\section{References}

Bourquin JP, Subramanian A, Langebrake C, Reinhardt D, Bernard O, Ballerini P, Baruchel A, Cave H, Dastugue N, 
Hasle $\mathrm{H}$, et al. 2006. Identification of distinct molecular phenotypes in acute megakaryoblastic leukemia by gene expression profiling. Proc Natl Acad Sci 103: 3339-3344.

Bousquet M, Quelen C, Rosati R, Mansat-De Mas V, La Starza R, Bastard C, Lippert E, Talmant P, Lafage-Pochitaloff M, Leroux D, et al. 2008. Myeloid cell differentiation arrest by miR-125b-1 in myelodysplastic syndrome and acute myeloid leukemia with the $\mathrm{t}(2 ; 11)(\mathrm{p} 21 ; \mathrm{q} 23)$ translocation. I Exp Med 205: 2499-2506.

Carthew RW, Sontheimer EJ. 2009. Origins and mechanisms of miRNAs and siRNAs. Cell 136: 642-655.

Chen CZ, Li L, Lodish HF, Bartel DP. 2004. MicroRNAs modulate hematopoietic lineage differentiation. Science 303: 83-86.

Chou ST, Opalinska JB, Yao Y, Fernandes MA, Kalota A, Brooks JS, Choi JK, Gewirtz AM, Danet-Desnoyers GA, Nemiroff $\mathrm{RL}$, et al. 2008. Trisomy 21 enhances human fetal erythromegakaryocytic development. Blood 112: 4503-4506.

Dennis G Jr, Sherman BT, Hosack DA, Yang J, Gao W, Lane HC, Lempicki RA. 2003. DAVID: Database for annotation, visualization, and integrated discovery. Genome Biol 4: 3.

Dickins RA, Hemann MT, Zilfou JT, Simpson DR, Ibarra I, Hannon GJ, Lowe SW. 2005. Probing tumor phenotypes using stable and regulated synthetic microRNA precursors. Nat Genet 37: 1289-1295.

Elagib KE, Racke FK, Mogass M, Khetawat R, Delehanty LL, Goldfarb AN. 2003. RUNX1 and GATA-1 coexpression and cooperation in megakaryocytic differentiation. Blood 101: 4333-4341.

Forman JJ, Legesse-Miller A, Coller HA. 2008. A search for conserved sequences in coding regions reveals that the let-7 microRNA targets Dicer within its coding sequence. Proc Natl Acad Sci 105: 14879-14884.

Grimson A, Farh KK, Johnston WK, Garrett-Engele P, Lim LP, Bartel DP. 2007. MicroRNA targeting specificity in mammals: Determinants beyond seed pairing. Mol Cell 27: 91-105.

Hasle H. 2001. Pattern of malignant disorders in individuals with Down's syndrome. Lancet Oncol 2: 429-436.

He L, Thomson JM, Hemann MT, Hernando-Monge E, Mu D, Goodson S, Powers S, Cordon-Cardo C, Lowe SW, Hannon G), et al. 2005. A microRNA polycistron as a potential human oncogene. Nature 435: 828-833.

Hollanda LM, Lima CS, Cunha AF, Albuquerque DM, Vassallo J, Ozelo MC, Joazeiro PP, Saad ST, Costa FF. 2006. An inherited mutation leading to production of only the short isoform of GATA-1 is associated with impaired erythropoiesis. Nat Genet 38: 807-812.

Jandrig B, Seitz S, Hinzmann B, Arnold W, Micheel B, Koelble K, Siebert R, Schwartz A, Ruecker K, Schlag PM, et al. 2004. ST18 is a breast cancer tumor suppressor gene at human chromosome 8q11.2. Oncogene 23: 9295-9302.

Johnnidis JB, Harris MH, Wheeler RT, Stehling-Sun S, Lam MH, Kirak O, Brummelkamp TR, Fleming MD, Camargo FD. 2008. Regulation of progenitor cell proliferation and granulocyte function by microRNA-223. Nature 451: 1125-1129.

Johnson JJ, Chen W, Hudson W, Yao Q, Taylor M, Rabbitts TH, Kersey JH. 2003. Prenatal and postnatal myeloid cells demonstrate stepwise progression in the pathogenesis of MLL fusion gene leukemia. Blood 101: 3229-3235.

Karube Y, Tanaka H, Osada H, Tomida S, Tatematsu Y, Yanagisawa K, Yatabe Y, Takamizawa J, Miyoshi S, Mitsudomi T, et al. 2005. Reduced expression of Dicer associated with poor prognosis in lung cancer patients. Cancer Sci 96: 111-115.

Klein C, Grudzien M, Appaswamy G, Germeshausen M, Sandrock I, Schaffer AA, Rathinam C, Boztug K, Schwinzer B, Rezaei N, et al. 2007. HAX1 deficiency causes autosomal recessive severe congenital neutropenia (Kostmann disease). Nat Genet 39: 86-92.

Klusmann JH, Creutzig U, Zimmermann M, Dworzak M, Jorch N, Langebrake C, Pekrun A, Macakova-Reinhardt K, Reinhardt D. 2008. Treatment and prognostic impact of transient leukemia in neonates with Down syndrome. Blood 111: 2991-2998.

Kumar MS, Lu J, Mercer KL, Golub TR, Jacks T. 2007. Impaired microRNA processing enhances cellular transformation and tumorigenesis. Nat Genet 39: 673-677.

Kumar MS, Pester RE, Chen CY, Lane K, Chin C, Lu J, Kirsch DG, Golub TR, Jacks T. 2009. Dicer1 functions as a haploinsufficient tumor suppressor. Genes \& Dev 23: 2700-2704.

Landgraf P, Rusu M, Sheridan R, Sewer A, Iovino N, Aravin A, Pfeffer S, Rice A, Kamphorst AO, Landthaler M, et al. 2007. A mammalian microRNA expression atlas based on small RNA library sequencing. Cell 129: 1401-1414.

Le MT, Teh C, Shyh-Chang N, Xie H, Zhou B, Korzh V, Lodish HF, Lim B. 2009. MicroRNA-125b is a novel negative regulator of p53. Genes \& Dev 23: 862-876.

Lee YS, Kim HK, Chung S, Kim KS, Dutta A. 2005. Depletion of human micro-RNA miR-125b reveals that it is critical for the proliferation of differentiated cells but not for the downregulation of putative targets during differentiation. I Biol Chem 280: 16635-16641.

Lewis BP, Burge CB, Bartel DP. 2005. Conserved seed pairing, often flanked by adenosines, indicates that thousands of human genes are microRNA targets. Cell 120: 15-20.

Li C, Wong WH. 2001. Model-based analysis of oligonucleotide arrays: Expression index computation and outlier detection. Proc Natl Acad Sci 98: 31-36.

Li Z, Godinho FJ, Klusmann JH, Garriga-Canut M, Yu C, Orkin SH. 2005. Developmental stage-selective effect of somatically mutated leukemogenic transcription factor GATA1. Nat Genet 37: 613-619.

Li Z, Tognon CE, Godinho FJ, Yasaitis L, Hock H, Herschkowitz JI, Lannon CL, Cho E, Kim SJ, Bronson RT, et al. 2007. ETV6NTRK3 fusion oncogene initiates breast cancer from committed mammary progenitors via activation of AP1 complex. Cancer Cell 12: 542-558.

Lu J, Getz G, Miska EA, Alvarez-Saavedra E, Lamb J, Peck D, Sweet-Cordero A, Ebert BL, Mak RH, Ferrando AA, et al. 2005. MicroRNA expression profiles classify human cancers. Nature 435: 834-838.

Lu J, Guo S, Ebert BL, Zhang H, Peng X, Bosco J, Pretz J, Schlanger R, Wang JY, Mak RH, et al. 2008. MicroRNAmediated control of cell fate in megakaryocyte-erythrocyte progenitors. Dev Cell 14: 843-853.

Malinge S, Izraeli S, Crispino JD. 2009. Insights into the manifestations, outcomes, and mechanisms of leukemogenesis in Down syndrome. Blood 113: 2619-2628.

Mizuno Y, Yagi K, Tokuzawa Y, Kanesaki-Yatsuka Y, Suda T, Katagiri T, Fukuda T, Maruyama M, Okuda A, Amemiya T, et al. 2008. miR-125b inhibits osteoblastic differentiation by down-regulation of cell proliferation. Biochem Biophys Res Commun 368: 267-272.

Mundschau G, Gurbuxani S, Gamis AS, Greene ME, Arceci RJ, Crispino JD. 2003. Mutagenesis of GATA1 is an initiating event in Down syndrome leukemogenesis. Blood 101: 42984300.

Pang L, Xue HH, Szalai G, Wang X, Wang Y, Watson DK, Leonard WJ, Blobel GA, Poncz M. 2006. Maturation stagespecific regulation of megakaryopoiesis by pointed-domain Ets proteins. Blood 108: 2198-2206.

Pui JC, Allman D, Xu L, DeRocco S, Karnell FG, Bakkour S, Lee JY, Kadesch T, Hardy RR, Aster JC, et al. 1999. Notch1 
Klusmann et al.

expression in early lymphopoiesis influences $\mathrm{B}$ versus $\mathrm{T}$ lineage determination. Immunity 11: 299-308.

Rainis L, Toki T, Pimanda JE, Rosenthal E, Machol K, Strehl S, Gottgens B, Ito E, Izraeli S. 2005. The proto-oncogene ERG in megakaryoblastic leukemias. Cancer Res 65: 7596-7602.

Salek-Ardakani S, Smooha G, de Boer J, Sebire NJ, Morrow M, Rainis L, Lee S, Williams O, Izraeli S, Brady HJ. 2009. ERG is a megakaryocytic oncogene. Cancer Res 69: 4665-4673.

Scott GK, Goga A, Bhaumik D, Berger CE, Sullivan CS, Benz CC. 2007. Coordinate suppression of ERBB2 and ERBB3 by enforced expression of micro-RNA miR-125a or miR-125b. I Biol Chem 282: 1479-1486.

Shi XB, Xue L, Yang J, Ma AH, Zhao J, Xu M, Tepper CG, Evans CP, Kung HJ, deVere White RW. 2007. An androgen-regulated miRNA suppresses Bak1 expression and induces androgenindependent growth of prostate cancer cells. Proc Natl Acad Sci 104: 19983-19988.

Skokowa J, Lan D, Thakur BK, Wang F, Gupta K, Cario G, Brechlin AM, Schambach A, Hinrichsen L, Meyer G, et al. 2009. NAMPT is essential for the G-CSF-induced myeloid differentiation via a $\mathrm{NAD}^{+}$-sirtuin-1-dependent pathway. Nat Med 15: 151-158.

Sonoki T, Iwanaga E, Mitsuya H, Asou N. 2005. Insertion of microRNA-125b-1, a human homologue of lin-4, into a rearranged immunoglobulin heavy chain gene locus in a patient with precursor B-cell acute lymphoblastic leukemia. Leukemia 19: 2009-2010.

Stankiewicz MJ, Crispino JD. 2009. ETS2 and ERG promote megakaryopoiesis and synergize with alterations in GATA-1 to immortalize hematopoietic progenitor cells. Blood 113: 3337-3347.

Subramanian A, Tamayo P, Mootha VK, Mukherjee S, Ebert BL, Gillette MA, Paulovich A, Pomeroy SL, Golub TR, Lander ES, et al. 2005. Gene set enrichment analysis: A knowledgebased approach for interpreting genome-wide expression profiles. Proc Natl Acad Sci 102: 15545-15550.

Tetteroo PA, Massaro F, Mulder A, Schreuder-van Gelder R, dem Borne AE. 1984. Megakaryoblastic differentiation of proerythroblastic K562 cell-line cells. Leuk Res 8: 197-206.

Tokumaru S, Suzuki M, Yamada H, Nagino M, Takahashi T. 2008. let-7 regulates Dicer expression and constitutes a negative feedback loop. Carcinogenesis 29: 2073-2077.

Tunstall-Pedoe O, Roy A, Karadimitris A, de la Fuente J, Fisk NM, Bennett P, Norton A, Vyas P, Roberts I. 2008. Abnormalities in the myeloid progenitor compartment in Down syndrome fetal liver precede acquisition of GATA1 mutations. Blood 112: 4507-4511.

Viswanathan SR, Daley GQ, Gregory RI. 2008. Selective blockade of microRNA processing by Lin28. Science 320: 97-100.

Wechsler J, Greene M, McDevitt MA, Anastasi J, Karp JE, Le Beau MM, Crispino JD. 2002. Acquired mutations in GATA1 in the megakaryoblastic leukemia of Down syndrome. Nat Genet 32: 148-152.

Xiao C, Calado DP, Galler G, Thai TH, Patterson HC, Wang J, Rajewsky N, Bender TP, Rajewsky K. 2007. MiR-150 controls $\mathrm{B}$ cell differentiation by targeting the transcription factor c-Myb. Cell 131: 146-159.

Yang J, Siqueira MF, Behl Y, Alikhani M, Graves DT. 2008. The transcription factor ST18 regulates proapoptotic and proinflammatory gene expression in fibroblasts. FASEB J 22: 39563967. 


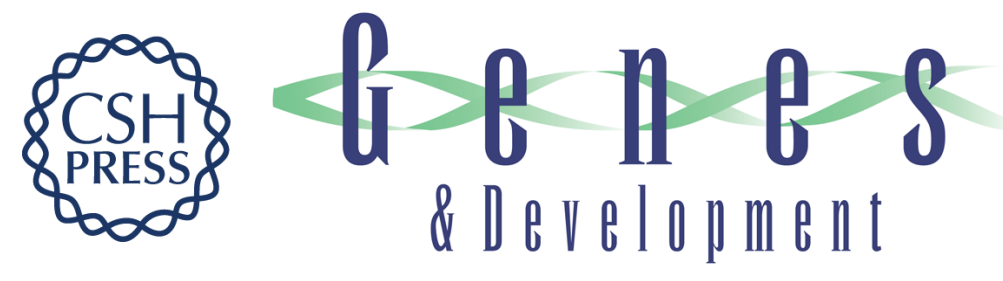

\section{miR-125b-2 is a potential oncomiR on human chromosome 21 in megakaryoblastic leukemia}

Jan-Henning Klusmann, Zhe Li, Katarina Böhmer, et al.

Genes Dev. 2010, 24:

Access the most recent version at doi:10.1101/gad.1856210

Supplemental
Material http://genesdev.cshlp.org/content/suppl/2010/02/18/24.5.478.DC1

References This article cites 50 articles, 23 of which can be accessed free at: http://genesdev.cshlp.org/content/24/5/478.full.html\#ref-list-1

License Freely available online through the Genes \& Development Open Access option.

Email Alerting Receive free email alerts when new articles cite this article - sign up in the box at the top Service right corner of the article or click here.

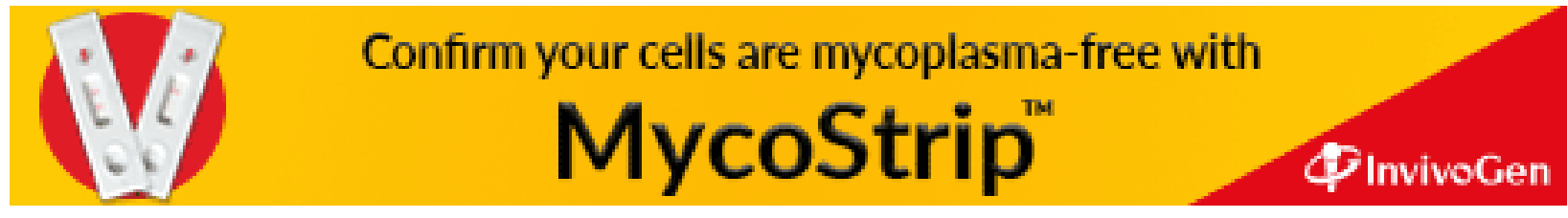

